\title{
E-BRIEF
}

September 7, 2016

HEALTHCARE POLICY

\section{Healthcare Spending Decelerating? Not so Fast!}

\author{
by
}

William B.P. Robson

- The Canadian Institute for Health Information's 2015 National Health Expenditures report shows a sharp deceleration in provincial health budgets - reassuring in light of concerns about the long-term fiscal sustainability of publicly funded healthcare in Canada.

- Each NHEX report's figures for its two most recent years, however, rest mainly on budget estimates. Later revisions based on actual numbers typically have shown materially larger increases. Revised estimates for 2014 in the 2015 report show yet another overshoot, and an upward turn in spending growth.

- Part of the explanation for health spending overshoots seems to be positive revenue "surprises" that undermine fiscal discipline: when governments reap more revenue than they budgeted for, they spend more than they budgeted for - including on healthcare. More realistic revenue projections and better scrutiny of in-year spending decisions could help hold healthcare spending increases in line with Canadians' willingness to pay.

The long-term sustainability of publicly funded healthcare in Canada is a major concern in finance ministries, among policy wonks and increasingly for the public. The fiscal backdrop is sobering: slower economic growth is pinching government revenues, while most governments already have sizable debts, interest payments and unfunded liabilities. Healthcare costs rose rapidly in the past, and population aging is a chronic source of upward pressure. So growth rates of healthcare spending by provincial and territorial governments - the governments that actually deliver most of these services - attract attention.

I thank Jennifer Tsao for assistance compiling budget data, and Colin Busby and a number of members of the C.D. Howe Institute's Health Policy Council for valuable comments on earlier drafts. Responsibility for the conclusions and policy recommendations in this paper, and for any remaining errors, is mine. 
If governments could reliably hit their budget targets, concerns about healthcare's pressure on public finances would be less acute. Fiscal planners know growth of spending cannot outpace growth of the economy forever, and government budgets typically project decelerations in spending, healthcare included. But, as work by the C.D. Howe Institute on fiscal targets has shown, budgets are not reliable guides to results: governments typically spend more than they project. And, as this E-Brief documents, the most widely followed compilation of healthcare spending in Canada - the National Health Expenditures (NHEX) database from the Canadian Institute for Health Information (CIHI) - reflects this pattern. Preliminary estimates for each year typically show growth in health spending that is significantly lower than what the final numbers show.

In short, the headline current-year numbers exaggerate the downward bending of the healthcare cost curve. Meeting the challenge of sustainability in healthcare spending is not only about restrained goals in provincial budgets; it is also about the controls and discipline that turn those budget goals into results.

\section{Growth of Government Spending on Healthcare}

The CIHI's NHEX is a unique aggregation of different types of healthcare spending from government and private sources, and each annual edition gets widespread attention. A major theme of the past few years' releases has been slower growth in spending by provinces and territorial governments. The 2015 NHEX report emphasized modest recent increases (CIHI 2015), and each of its predecessors in 2012, 2013 and 2014 (CIHI 2012, 2013, 2014) highlighted decelerations from prior growth rates observers often characterized as fiscally unsustainable. If, as Mendelsohn and Falk (2013) commented after the release of the 2013 NHEX report, Canada truly has "bent the cost curve," growth in healthcare budgets now might be in line with, or even below, growth in the economy and the tax base - alleviating the threat that fiscal pressures will force changes Canadians would not otherwise choose to make.

The problem with drawing strong conclusions from the latest years in the database, however, is that the CIHI does not have actual, audited spending numbers for the publication year of its NHEX reports, or for the prior year. For those years, the CIHI uses budget and spending estimates; it revises the numbers in later reports as actual spending data become available from the respective governments after the end of their fiscal years on March 31. For example, 2013 is the most recent year for which the 2015 report uses final data; the 2015 report's figures for 2015 and 2014 are largely or partially estimated. The CIHI marks the latest two years in its tables with an "f" to indicate that the figures for those years are forecasts. ${ }^{1}$

Looking more closely at the good news in the 2015 NHEX report, then, its estimates for 2015 show increases in provincial and territorial health spending of only 1.5 percent. ${ }^{2}$ That extends the positive trend in previous reports: growth rates in the preliminary estimates dropped from 6 percent and more in the 2000s to 4 percent and less in the current decade. The understandable focus of those who examine the NHEX's estimates for the current year, however, has led them to overlook a less happy fact: the actual numbers based on audited

1 Further revisions to years not marked with an "f" sometimes occur when late or revised actual figures become available.

2 Except where noted, all references to changes in spending are in current dollars. Ideally, one would be able to distinguish changes adjusted for inflation from changes due to prices alone, but good measures of price changes in healthcare services are not available. 
financial statements after a two-year lag typically show larger increases. From the first NHEX report in 1998 through to 2011, the revised growth rates for provincial and territorial spending across the country were, on average, 0.9 percent higher than the preliminary ones. Over that period, moreover, upward revisions outweighed downward ones in each province and territory. This worrying pattern did not hold in 2012 and 2013: the final numbers for those two years averaged 0.3 percent below the preliminary ones for the country as a whole, and most provinces and territories recorded increases below projections.

Disappointingly, however, the 2015 report's first revisions for 2014 revert to the old pattern of overshoots. Although the preliminary numbers in the 2014 NHEX report suggested that government health budgets would grow 1.9 percent that year - a number that attracted widespread positive comment at the time - the largely unnoticed revisions in the 2015 NHEX report show spending up by 3.3 percent in 2014, with 10 of the 13 provinces and territories spending more than the preliminary numbers for that year showed. Experience suggests that the very low growth for 2015 in the latest NHEX report might prove to be partly the result of optimistic forecasts. Durable progress in restraining healthcare budgets requires governments not just to make subdued growth projections, but to deliver on them.

\section{The Challenge of Hitting Budget Targets}

Highlighting one upward revision in health spending estimates in 2014 after downward revisions in 2012 and 2013 might seem unduly gloomy - especially when the preliminary increases in all three years were so much lower than historical growth rates. But the upward revision to 2014 is not just a reversion to previous form: it fits a larger pattern of overshoots of governments' budget targets. As a series of C.D. Howe Institute reports has documented - most recently, Busby and Robson (2016) - over the past 15 years the federal and provincial governments have tended to report both revenues and spending that were higher than their budgets anticipated. The revisions in successive NHEX reports suggest that this bias toward overshooting affects healthcare, as it affects spending in general.

Beginning with the first NHEX report in 1998, each has provided historical figures since 1975 and estimates for the year of the report and the previous year. As noted, the estimates for the ultimate and penultimate years are marked with an "f," for forecast. So one can compare successive editions of the report to see how the CIHI revised each year's initial estimates once final figures were in. ${ }^{3}$ In the 2015 report, 2013 is the most recent year based on final numbers, so the report provides 16 years (1998 to 2013) of final numbers that one can compare to the initial estimates for those years, as well as a revised (though not yet final) figure for 2014 that one can compare to the initial estimates for that year.

The resulting comparison (Figure 1) reveals both good and bad news. From 1998 to 2011, provincial and territorial spending grew, on average, 7 percent annually - well ahead of Canada's long-term potential economic growth. The good news is that the actual numbers to 2013 (the gold bars in the figure) confirm a significant deceleration in provincial and territorial government healthcare spending since 2011 - to a growth rate lower than 3 percent, which would present much less of a challenge to fiscal sustainability.

3 For example, one can compare the increases shown for 1998 in the 1998 NHEX report with the increases shown for 1998 in the 2015 report, the increases shown for 1999 in the 1999 report with those for 1999 in the 2015 report and so on. 
Figure 1: Provincial and Territorial Government Healthcare Spending - Preliminary versus Actual Growth, 1998-2015

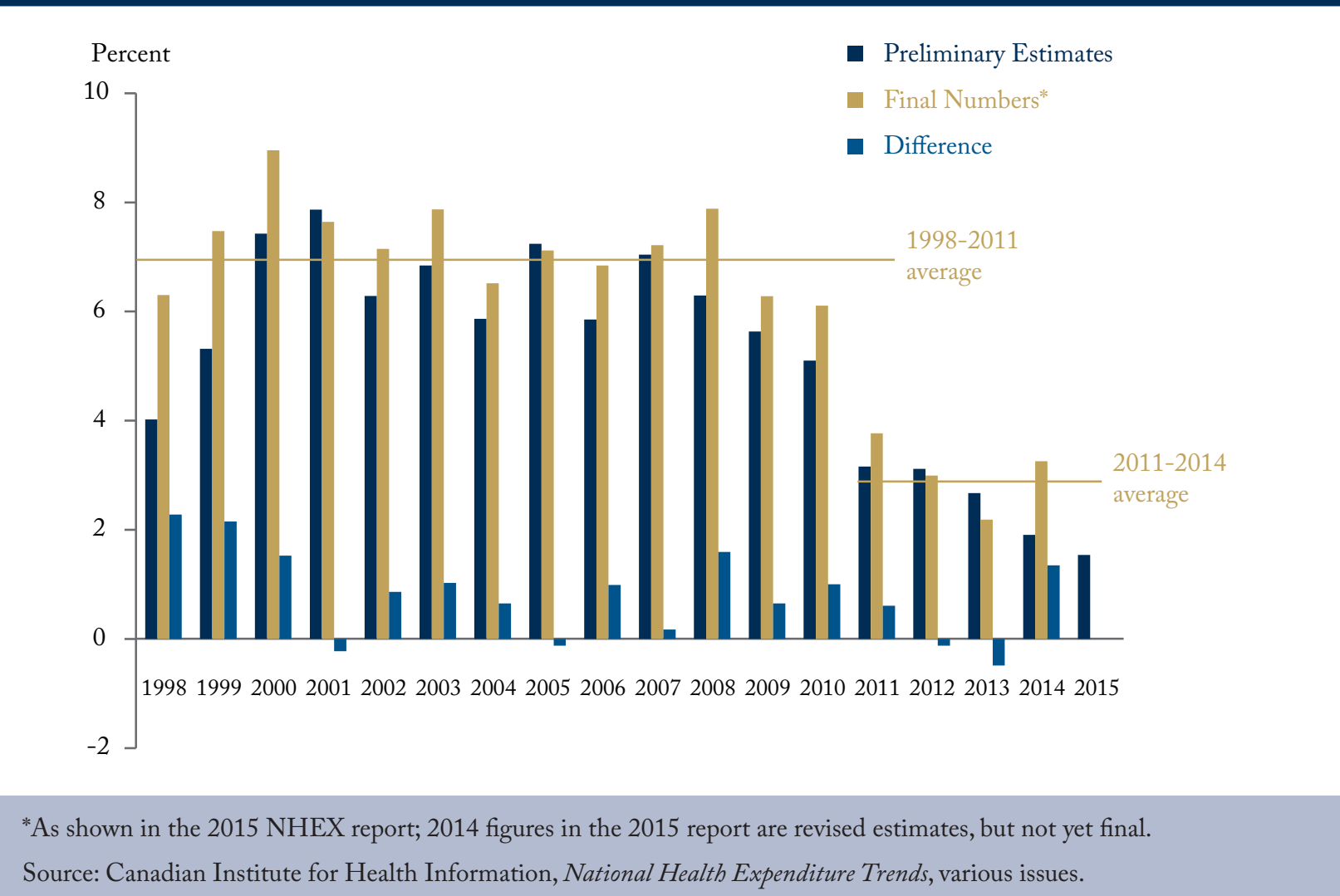

The bad news, however, is how consistently the preliminary figures for each report's publication year (the dark blue bars) understate the final figures. Between 1998 and 2011, the numbers based on audited figures exceeded preliminary estimates by an average of 0.9 percent (the light blue bars show the difference between the preliminary and final, or revised, numbers). And although 2012 and 2013 were exceptions, the 2015 NHEX report's revised estimate for 2014 boosts the increase for that year by 1.3 percent. If that figure stands up when the final numbers come out, the average upward revision over the entire period covered by the NHEX reports would also be close to 0.9 percent.

\section{Healthcare Overruns and Fiscal Sustainability}

An overshoot of 0.9 percent in a single year would be no big deal: no organization hits budget targets exactly, and no reasonable person would expect it of governments. But overshoots of that size year after year matter: since 1998, the year of the first NHEX report, they compound to almost 15 percent. Scaled to 2015 budgets, that cumulative overshoot implies that governments' healthcare spending last year would have been about $\$ 20$ billion lower - roughly equal to the entire healthcare budgets of Alberta or British Columbia - if the budget-based preliminary numbers since 1998 had been borne out. ${ }^{4}$

4 The 2015 NHEX report estimates healthcare spending for that year at $\$ 144.3$ billion. 
Consistent overshoots of that size can also affect judgments about sustainability. No credible estimate of Canada's sustainable rate of economic growth in the decades ahead exceeds 2 percent in inflation-adjusted terms. Allowing for 2 percent inflation, as targeted by the Bank of Canada, nominal growth in gross domestic product and the tax base would not exceed 4 percent. With such a growth rate, healthcare spending increases of, say, 3.5 percent - the average of the preliminary estimates from 2010 to 2013, the most recent year with final figures in the 2015 NHEX report - would be easy to manage. Indeed, over time, they would leave fiscal room for growth in other programs, debt retirement and tax relief. Healthcare spending increases 0.9 percent larger than that, however -4.4 percent each year - would threaten erosion of other programs, rising debt and tax hikes.

\section{Options for Better Spending Control}

One cannot rule out that governments might deliberately budget healthcare increases that are unsustainable: the federal government's 6 percent annual increases in the Canada Health Transfer clearly exceed the economy's growth rate. Yet, overtly unsustainable policies seem, on the whole, to be a less problematic threat than unplanned overruns - the kind of unbudgeted healthcare spending increases seen in most years since 1998. So a natural question is: what changes in the environment could make budget overshoots less likely?

The C.D. Howe Institute's fiscal accountability reports recommend several improvements to the quality of government financial reports and to the oversight exercised by parliamentary committees and other bodies. When it comes to healthcare spending in particular, tools such as capitation and salaried remuneration of physicians (Blomqvist and Busby 2012, 2015), and deductibles and co-payments affecting patients might help governments encourage behaviour more consistent with their budgetary goals.

The fiscal accountability reports also reveal a prime suspect behind governments" tendency toward "surprise" spending: "surprise" revenue. Missed spending targets - in either direction, though overshoots occur much more than undershoots - tend to coincide with missed revenue targets in the same direction. When revenue comes in lower than budgeted, spending also tends to come in lower than budgeted; when - as has been more common since the late 1990s - revenue comes in higher than budgeted, so does spending.

A look at healthcare overruns since 1998 by province alongside revenue overshoots over the same period (Figure 2) suggests that revenue surprises account for some of governments' tendency to exceed their healthcare budgets. ${ }^{5}$ But that is not the entire story: the annual figures are more varied, and the resource boom produced outsized revenue surprises in Newfoundland and Labrador, Saskatchewan and Alberta, while healthcare spending

5 Comparing over- and undershoots of total revenue and spending (as in Busby and Robson 2016) with revisions to the CIHI numbers for healthcare spending on an annual basis is not straightforward. Governments budget and report using fiscal years that run from April 1 to March 31, while the CIHI numbers cited here are for calendar years. Government budgets and public accounts use accrual accounting, which amortizes capital spending, while the CIHI looks at cash outlays. That noted, revisions to the CIHI's preliminary numbers are correlated with over- and undershoots in budgetary spending from 1998 to 2013 (using fiscal years with the nine-month overlap for the comparison) in nine of the ten provinces, Alberta being the sole exception. The correlation coefficients are not typically very large - only Saskatchewan and British Columbia have coefficients higher than 0.5 - and tell no definitive story about cause and effect. The annual correlations between healthcare revisions and revenue over- and undershoots are positive in six provinces, with Quebec and British Columbia showing values higher than 0.5, and Prince Edward Island, New Brunswick and Saskatchewan showing values between 0.4 and 0.5 . 


\section{Figure 2: Average Healthcare Overshoots and Revenue Surprises by Province, 1998-2014}

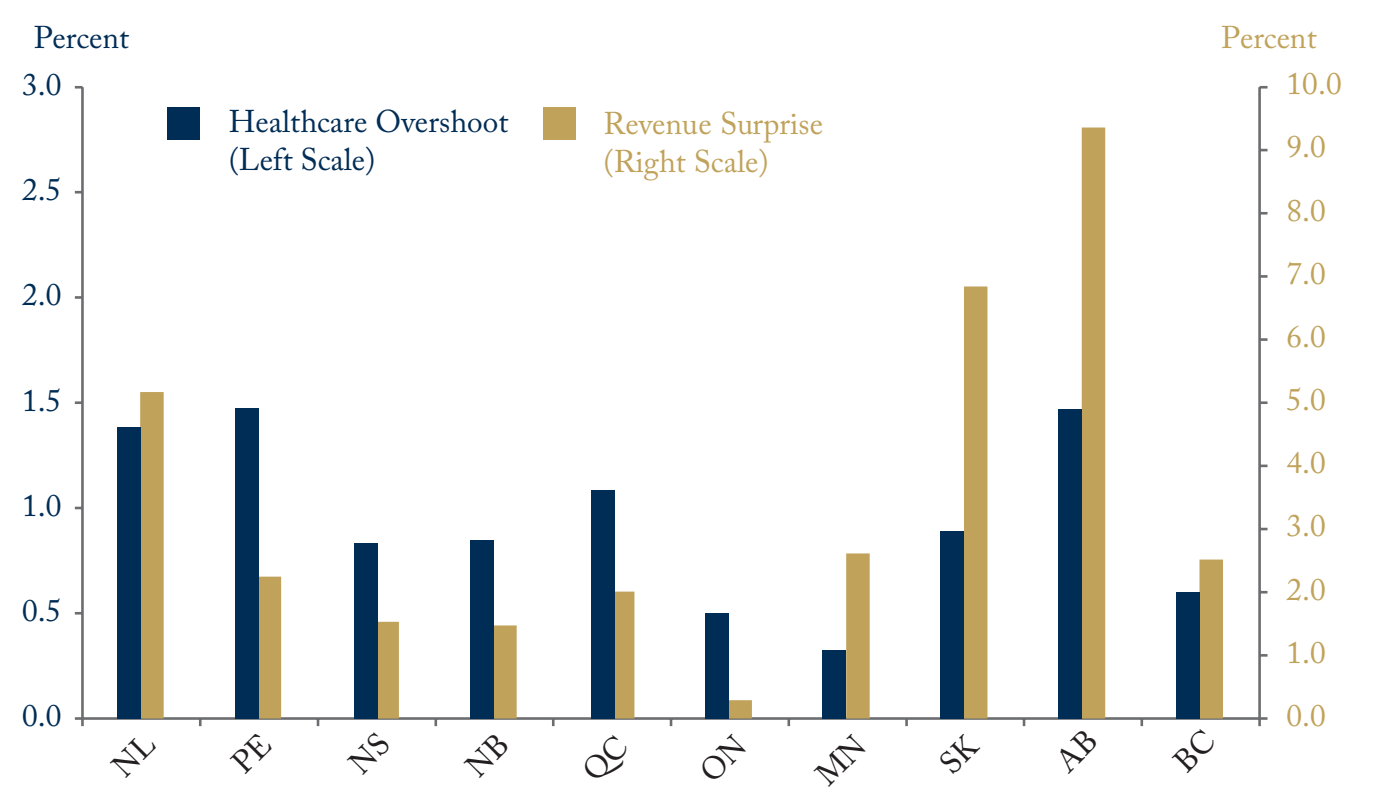

Sources: Canadian Institute for Health Information, National Health Expenditure Trends, various issues; provincial and territorial budgets and public accounts, various years (see Busby and Robson 2016).

in those provinces tended to exceed targets by smaller amounts. In the struggle to improve this record, however, governments should not overlook any potentially useful option.

Some responses to the tendency for revenue surprises to erode budgetary discipline apply to any category of spending, including healthcare. One is to avoid deliberately underprojecting revenue, which governments often do to improve their chances of hitting a bottom-line target. Instead, they could include an explicit "prudence cushion" in their projections or a contingency reserve in spending. Alternatively, they could introduce explicit rules about allocating higher-than-expected revenue - although these types of commitments have proved tough to meet in practice.

Another potentially important factor in provincial and territorial healthcare budgets is transfers from the federal government. A thorough investigation of the possible influence of these transfers would require annual data on differences between what the provinces project for healthcare-related or total transfers from Ottawa in their annual budgets and what they actually get. For hints about what one might find, one can look at healthcare over- and undershoots in calendar years alongside changes in federal transfers over the two fiscal years containing those calendar years, which would give a sense of the degree to which Ottawa is easing or intensifying provincial and territorial budget constraints (Figure 3).

Some changes in federal transfers have come as a surprise to provinces, while others have come after negotiations and announcements, so no simple story can relate them to in-year changes in healthcare spending. The mid-2000s expansion of transfers - largely driven by the healthcare accord that then-Prime Minister Paul Martin characterized as a "fix for a generation" - prompted major increases in the provinces' 2005 projected 


\section{Figure 3: Healthcare Overshoots and Two-Year Changes in Federal Transfers, 2000-2014}

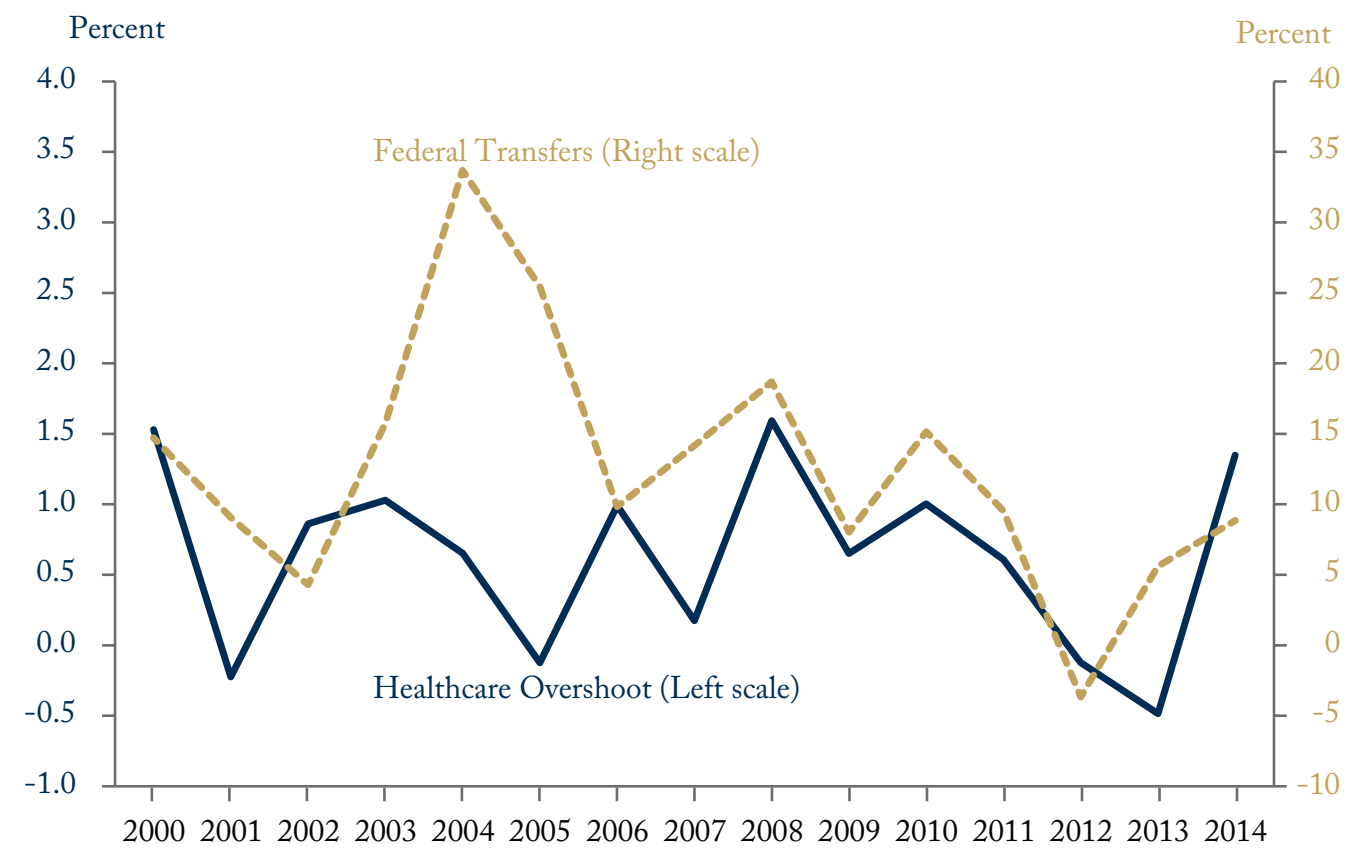

Note: The figure starts in 2000 because the Northwest Territories and Nunavut were a single territory before that.

Sources: Canadian Institute for Health Information, National Health Expenditure Trends, various issues; Canada, Department of Finance, "Fiscal Reference Tables 2015"; author's calculations.

healthcare spending (evident in Figure 1), which final CIHI data show they failed to achieve. The pattern over the subsequent decade, however, suggests that changes in federal transfers might have affected in-year spending discipline. The deceleration in federal transfers until 2012 might have intensified cost control and, very tentatively, their acceleration since then might have fostered the return to overshoots in 2014.

Another insight into the role of federal transfers might come from comparing "surprises" in that particular source of revenue - as calculated by the difference between Canada Health Transfers anticipated in a province's annual budget and reported after yearend in its public accounts - and "surprises" in healthcare spending. As noted earlier, the data in provincial budgets and public accounts are not directly comparable to CIHI data. Moreover, provinces do not show expected federal transfers in their budgets consistently across the country or over time. As a first step, however, Figure 4 shows this comparison for the largest province, Ontario.

As with Figure 3, the pattern of Canada Health Transfer over- and undershoots and of healthcare spending over- and undershoots does not tell a definitive story. But the tendency of the two lines to move together is unmistakable, and suggests that unexpectedly high or low federal transfers did affect budgetary discipline in Ontario's healthcare spending. The new government in Ottawa so far has resisted pressure for further increases in healthcare and other transfers to the provinces. Ideally, further investigation of this relationship would precede any changes to health-related transfers. Changes in federal transfers that lessened provincial vigilance over healthcare spending would not aid the cause of long-term sustainability (Di Matteo and Busby 2016). 


\section{Figure 4: Canada Health Transfers and Healthcare Spending, Budget versus Actual, Ontario, Fiscal Years 1998/99 to 2014/15}

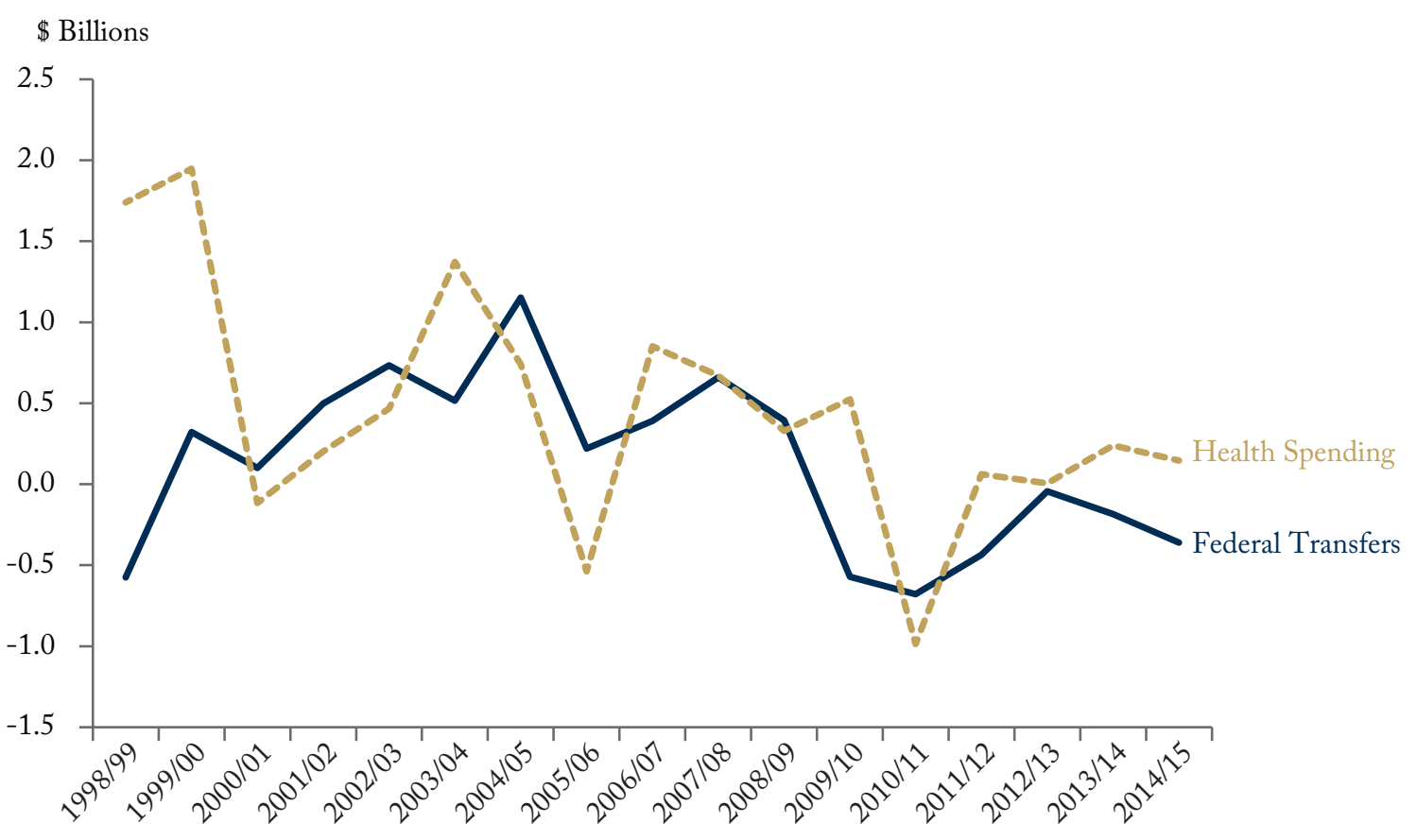

Source: Ontario government budgets and public accounts for years shown.

\section{Bending the Healthcare Cost Curve}

To recap the good news, the CIHI's NHEX reports show that Canadian governments have reduced growth in healthcare costs since 2011. The 2015 report shows actual provincial and territorial spending growth in 2012 and 2013 of 3.0 percent and 2.2 percent, respectively - rates that should be sustainable even in a slowgrowth economy. Also remarkable is that those growth rates were slower than the preliminary estimates for those years in the 2012 and 2013 NHEX reports - an encouraging change after 14 years dominated by significant upward revisions.

The bad news is that the downward revisions in 2012 and 2013 were so unusual. The 2015 report's revised figures for 2014 show a growth rate of 3.3 percent for that year - still in the range of sustainability, but 1.3 percent faster than the preliminary estimate in the 2014 report. If the historical pattern of 0.9 percent average overruns were to re-emerge, the message from each year's preliminary NHEX numbers - that publicly funded healthcare in Canada has become fiscally sustainable - might not be reliable.

Provincial and territorial governments could improve their chances of hitting ambitious targets for healthcare spending control through reforms that make providers and patients more sensitive to budget constraints, and through measures that improve budgetary control generally - particularly safeguards against unplanned spending when revenue comes in ahead of projections. All senior governments should guard against increases 
in federal transfers that could undermine the progress provinces and territories are making in bending Canada's healthcare cost curve down.

All Canadians, as users of publicly funded healthcare, as healthcare providers, as taxpayers and as citizens, have an interest in the fiscal sustainability of the healthcare system. Ensuring that provincial and territorial governments hit their healthcare spending targets is critical to that sustainability. 


\section{References}

Blomqvist, Åke, and Colin Busby. 2012. How to Pay Family Doctors: Why "Pay per Patient" is Better Than Fee for Service. Commentary 365. Toronto: C.D. Howe Institute. October

2015. Rethinking Canada's Unbalanced Mix of Public and Private Healthcare: Insights from Abroad. Commentary 420. Toronto: C.D. Howe Institute. February.

Busby, Colin, and William Robson. 2016. Controlling the Public Purse: The Fiscal Accountability of Canada's Senior Governments, 2016. Commentary 448. Toronto: C.D. Howe Institute. April.

CIHI (Canadian Institute for Health Information). 2012. "Canada's health care spending slows.” Ottawa. Available online at www.cihi.ca/CIHI-ext-portal/internet/en/Document/ spending+and+health+workforce/spending/RELEASE_30OCT12.

2013. “Canada curbs health spending as expenditures reach $\$ 211 \mathrm{~B}$.” Ottawa. Available online at https://www.cihi.ca/en/canada-curbs-health-spending-as-expenditures-reach-211b.

2014. “Canada's health spending hits slowest growth rate since 1997.” Ottawa. Available online at https://www.cihi.ca/en/spending-and-health-workforce/spending/canadas-health-spendinghits-slowest-growth-rate-since-1997.

2015. "Canada's slow health spending growth continues." Ottawa. Available online at https://www.cihi.ca/en/spending-and-health-workforce/spending/canadas-slow-health-spendinggrowth-continues.

Di Matteo, Livio and Colin Busby. 2016. Hold the Applause: Why Provincial Restraint on Healthcare Might Not Last. Commentary 455. Toronto: C.D. Howe Institute. July.

Mendelsohn, Matthew, and Will Falk. 2013. "How Canada's health care reformers quietly bent the cost curve." Healthydebate: Opinions, November 6. Available online at http://healthydebate.ca/opinions/ defying-expectations-how-health-care-reformers-quietly-bent-canadas-cost-curve.

This E-Brief is a publication of the C.D. Howe Institute.

William B.P. Robson is President and CEO of the C.D. Howe Institute.

This E-Brief is available at www.cdhowe.org.

Permission is granted to reprint this text if the content is not altered and proper attribution is provided. 